\title{
A criança e o adolescente com problemas do desenvolvimento no ambulatório de pediatria
}

\author{
Children and adolescents with developmental disabilities in the pediatric outpatient clinic
}

\author{
Luci Pfeiffer Miranda ${ }^{1}$, Rosa Resegue ${ }^{2}$, Amira Consuelo de Melo Figueiras ${ }^{3}$
}

\section{Resumo}

Objetivo: revisar a literatura e os princípios básicos sobre o atendimento ambulatorial da criança e do adolescente com alterações no desenvolvimento, salientando os aspectos da prevenção, detecção e intervenção precoce, inclusão e reabilitação.

Fonte de dados: pesquisa nas bases de dados Medline, Lilacs, nas publicações de comitês científicos, de instituições para portadores de necessidades especiais e protocolos sobre assistência ambulatorial em centros de referência para crianças e adolescentes portadores de deficiências.

Síntese dos dados: esta população-alvo apresenta, além dos problemas de saúde típicos de sua faixa etária, os relacionados a sua patologia de base, ou às consequiências dessas. Este artigo traz ao pediatra as principais causas de distúrbios de desenvolvimento e as características de cada forma de deficiência, ressaltando os cuidados necessários na sua abordagem nos ambulatórios de pediatria.

Conclusões: o censo brasileiro de 2000 aponta que $14,5 \%$ da população brasileira apresenta algum tipo de deficiência, posicionando os problemas de desenvolvimento como um dos mais prevalentes agravos da infância e da adolescência. Assim sendo, todo pediatra há que estar atento ao desenvolvimento das crianças e adolescentes e aos fatores que possam influir sobre ele. Do pediatra depende a prevenção, o diagnóstico precoce e o tratamento em tempo hábil, sendo insubstituível na coordenação da assistência multidisciplinar, bem como na inclusão desta clientela na assistência básica à saúde, fundamentais na definição do prognóstico e da qualidade de vida dos portadores de deficiências.

J Pediatr (Rio J) 2003;79(Supl.1):S33-S42: desenvolvimento infantil, deficiências do desenvolvimento, criança, adolescente, prevenção, diagnóstico, reabilitação.

\begin{abstract}
Objective: to review the literature on outpatient care of children and adolescents with developmental disabilities, focusing on prevention, early diagnosis, treatment, outcomes and rehabilitation.

Sources of data: search of Medline and Lilacs databases; publications of scientific committees of institutions for children with special needs; and outpatient care reports of reference centers for the treatment of children and adolescents with mental and developmental disabilities.

Summary of the findings: this population presents health problems associated with the basic pathology and its consequences in addition to the usual problems of the specific age group. The etiology of developmental disorders and the main characteristics of each type of disability are discussed. Special attention is given to outpatient pediatric care.

Conclusions: the most recent study of the Brazilian population, performed in 2000 , showed that $14.5 \%$ of this population presented some type of developmental deficiency. Therefore, developmental problems are one of the most prevalent health problems among children and adolescents. Consequently, pediatricians need to be prepared to evaluate and identify factors that may influence normal children development. Pediatricians are responsible for prevention, early diagnosis and coordination of the multidisciplinary treatment of these patients in addition to basic medical assistance, which is essential to guarantee the patients' good quality of life.
\end{abstract}

J Pediatr (Rio J) 2003;79(Supl.1):S33-S42: child development, development disabilities, child, adolescent, diagnosis, prevention, rehabilitation.

1. Coordenadora do Grupo de Trabalho - Crianças e Adolescentes Especiais, da SBP. Membro da Força-Tarefa de Prevenção da Deficiência Auditiva e do Departamento Científico de Segurança da SBP. Membro da Coordenação Municipal da Rede de Proteção às Crianças e Adolescentes de Curitiba, PR.

2. Coordenadora do Projeto Desenvolver do Programa de Integração Docente Assistencial da Universidade Federal de São Paulo (UNIFESP) - Município de Embu, SP. Pediatra da Disciplina de Pediatria Comunitária e Ambulatorial da UNIFESP. Membro do Departamento de Pediatria Ambulatorial da SBP.

3. Professora Auxiliar do Departamento de Assistência Materno-Infantil II da Universidade Federal do Pará. Pediatra do Programa de Estimulação Precoce da Unidade de Referência Especializada Materno-Infantil-Adolescente. Assessora da área da criança da Secretaria Municipal de Saúde de Belém-PA. Membro do Grupo de Trabalho - Crianças e Adolescentes Especiais, da SBP. 


\section{Introdução}

De acordo com dados da Organização Mundial de Saúde - OMS, em tempos de paz, pelo menos $10 \%$ das crianças de qualquer país nascem ou adquirem impedimentos, físicos, mentais ou sensoriais, que interferirão no seu desenvolvimento ${ }^{1}$.

Em nosso país, o censo de 2000 aponta para uma prevalência de cerca de 24,5 milhões de pessoas portadoras de deficiência, o que corresponde a $14,5 \%$ da população brasileira $^{2}$. No entanto, segundo documento do Ministério da Saúde, em 1991, apenas 2\% destes indivíduos recebiam algum tipo de assistência, quer seja da iniciativa privada ou do setor público, verificando-se inexpressivo avanço nessa situação ${ }^{3}$.

As raízes dessa situação estão no processo histórico das políticas públicas referentes à assistência em saúde e reabilitação desses indivíduos, que, ao longo dos anos, caracterizou-se pelo repasse de recursos financeiros para instituições filantrópicas, mantendo a atenção à deficiência no âmbito do assistencialismo e humanitarismo ${ }^{3}$.

Considerando-se os números acima, tem-se uma prevalência muito maior de crianças e de adolescentes portadores de deficiência do que de qualquer outra patologia e, no entanto, eles não estão incluídos nos protocolos de atendimento, na maioria dos ambulatórios gerais de pediatria.

As crianças e adolescentes com alterações no seu desenvolvimento apresentam características diversas na necessidade de assistência, de acordo com sua doença de base e das limitações que lhes são impostas por ela, mas também estão sujeitas a todos os quadros infecciosos e problemas gerais, ditos próprios da infância e da adolescência.

É preciso, portanto, que o pediatra esteja instrumentalizado para incluir o portador de necessidades especiais em sua rotina de ambulatório. Neste artigo, serão abordados os aspectos mais voltados ao desenvolvimento neuropsicomotor da criança e suas disfunções, bem como as principais características das crianças e adolescentes portadores de deficiências e suas necessidades especiais, visando definir o papel do pediatra, tanto na prevenção e detecção precoce dos distúrbios de desenvolvimento como na assistência à saúde desses indivíduos.

\section{Conceito de desenvolvimento}

Conceituar o que vem a ser desenvolvimento não é tão simples, variando segundo o referencial teórico que se queira adotar e os aspectos que se queira abordar. Para o pediatra, tem-se a definição clássica de Marcondes et al. $(1991)^{4}$, que diz que "desenvolvimento é o aumento da capacidade do indivíduo na realização de funções cada vez mais complexas"; já o neuropediatra certamente pensará na maturação do sistema nervoso central; da mesma forma, o psicólogo estará pensando nos aspectos cognitivos, na inteligência, na inter-relação com o meio ambiente; enquanto que o psicanalista dará mais ênfase às relações e à constituição do psiquismo 5 .
Num conceito mais amplo, desenvolvimento infantil é um processo que se inicia desde a vida intra-uterina e envolve vários aspectos, como o crescimento físico, a maturação neurológica e a construção de habilidades relacionadas ao comportamento, às esferas cognitiva, social e afetiva da criança. Tem como produto tornar a criança competente para responder às suas necessidades e às do seu meio, considerando seu contexto de vida.

\section{Fatores de risco para distúrbios do desenvolvimento}

Define-se como fatores de risco uma série de condições biológicas ou ambientais que aumentam a probabilidade de déficits no desenvolvimento neuropsicomotor da criança ${ }^{6}$. Esta definição, embora didática, nem sempre é facilmente utilizada na prática cotidiana, uma vez que em muitas situações há a superposição de fatores biológicos e ambientais, acarretando uma maior probabilidade da ocorrência de danos $^{6-9}$. Alguns autores separam dos biológicos os riscos ditos estabelecidos, referindo-se a desordens médicas definidas, como os erros inatos do metabolismo, as malformações congênitas, a síndrome de Down e outras síndromes genéticas ${ }^{10}$.

Os riscos ambientais, relacionados ao meio familiar e ao ambiente geral em que a criança e o adolescente vivem, manifestam-se pela omissão ou ação, como oferta precária da assistência à saúde, falta ou desinteresse de recursos sociais e educacionais, ausência de políticas e ações de prevenção de acidentes, violência e outros ${ }^{7-9}$. Estão, em parte relacionados com a miséria, mas não unicamente dependentes dela, pois muitos deles, como os acidentes, a negligência e as outras formas de violência doméstica acontecem em todos os níveis socioeconômicos (Tabela 1).

As crianças consideradas como de muito alto risco, ou seja, aquelas com peso de nascimento inferior a $1.500 \mathrm{~g}$ e intercorrências neonatais muito importantes, sempre que possível, devem ser acompanhadas em centros de referência com equipe multidisciplinar, com vistas à detecção e intervenção precoces a qualquer sinal de distúrbio do desenvolvimento. No atendimento a essas crianças, é fundamental a realização de algumas recomendações, como:

- documente toda investigação, diagnósticos e tratamentos efetuados, entregando cópia para a família. Isto evitará a repetição de exames e orientará outros pediatras no acompanhamento futuro;

- oriente bem a família sobre a necessidade e o porquê de acompanhamento diferenciado;

- encaminhe para outras avaliações e especialistas, quando indicados, em tempo hábil para tratamento;

- promova a interação mãe-bebê, estimulando o pegar, o tocar, acariciar, a conversa, mesmo nas UTIs e para os bebês gravemente enfermos;

- o diagnóstico funcional é suficiente para o encaminhamento para intervenção precoce;

- esteja sempre atento à vigilância do desenvolvimento, e não hesite em solicitar a colaboração de outros especia- 
listas ou profissionais de outras áreas quando perceber atraso ou déficits.

\section{Detecção precoce dos distúrbios do desenvolvimento}

A identificação e intervenção precoces são fundamentais para o prognóstico das crianças com distúrbios do desenvolvimento, o que faz da avaliação deste processo parte indispensável de toda consulta pediátrica ${ }^{11}$.

De uma forma geral, quanto maior a gravidade da alteração do desenvolvimento de uma criança, maior é a precocidade de sua identificação pelo pediatra, assim como o comprometimento motor é mais percebido do que alterações de linguagem e cognitivas, comumente diagnosticadas somente após três ou quatro anos de idade, o que retarda o tratamento e a possibilidade de reabilitação ${ }^{11}$.

A avaliação do desenvolvimento inicia-se no momento em que a família entra no consultório e deve prolongar-se durante a anamnese e o exame físico da criança, sendo muitas vezes necessária sua continuidade em outras consultas, assim como o parecer de outros profissionais ${ }^{11}$.

É fundamental o conhecimento do contexto familiar e social em que a criança encontra-se inserida, bem como dados sobre o momento da família em que a criança foi

Tabela 1 - Principais fatores de risco para alterações no desenvolvimento

$\begin{array}{ll}\text { Biológicos } & \\ \text { Pré-natais } & \begin{array}{l}\text { Problemas maternos como hipertensão, diabetes e } \\ \text { cardiopatias } \\ \text { Infecções congênitas } \\ \text { Incompatibilidade Rh }\end{array} \\ & \text { Uso de álcool ou drogas durante a gestação } \\ \text { Perinatais } & \text { Prematuridade } \\ & \text { Baixo peso de nascimento, principalmente o peso } \\ & \text { inferior a 1.500g } \\ & \text { Retardo do crescimento intra-uterino } \\ & \text { Hipóxia neonatal grave } \\ & \text { Hiperbilirrubinemia } \\ & \text { Distúrbios metabólicos graves, como hipoglicemia } \\ \text { por hiperinsulinismo } & \text { Hemorragia intracraniana } \\ \text { Crise convulsiva no período perinatal } & \text { Infecções }\end{array}$

Pós-natais Meningites, encefalites ou outras infecções graves Traumatismos intencionais ou não intencionais

Estabelecidos

Síndromes genéticas-cromossômicas

Erros inatos

Malformações congênitas

Ambientais

Cuidados precários à saúde e ou educação

Fatores socioeconômicos

Ambiente familiar e/ou meio desfavorável acidentes violência gerada, se a gestação foi ou não desejada, quais as fantasias da mãe e familiares sobre a criança, quem é o responsável pelos seus cuidados, comoé sua rotina de vida e quais foram as mudanças ocorridas nas relações familiares após o nascimento da mesma ${ }^{11,12}$.

Deve-se obter, também, os dados relacionados a possíveis fatores de risco para distúrbios do desenvolvimento, desde a concepção à época de início das aquisições de habilidades da criança, sendo também de grande importância a opinião dos familiares sobre o processo evolutivo de sua criança. Há consenso na literatura de que os pais são bons observadores e detectores acurados das deficiências observadas nos filhos, mostrando uma alta sensibilidade, especificidade e valor preditivo da sua opinião na detecção de problemas no desenvolvimento dos mesmos ${ }^{13}$.

O exame físico geral e neurológico, a avaliação sensorial e das aquisições da criança compõem o tripé da avaliação do seu desenvolvimento ${ }^{11}$.

Nos lactentes, é importante o oferecimento de algum objeto que chame a atenção da criança, verificando-se seu interesse, sua coordenação e interação com sua mãe e examinador. Nas crianças maiores, a linguagem, lucidez e localização no tempo e espaço devem ser avaliadas. Lápis e papel são ferramentas auxiliares importantes, pois, através de desenhos ou tarefas elementares de escrita, pode-se perceber dados importantes quanto à compreensão, habilidades e motricidade ${ }^{11,12}$.

No exame físico, algumas características podem sugerir doenças que cursam com alterações no desenvolvimento, sendo importante estar atento para os parâmetros de peso, estatura e perímetro cefálico; observar a presença de anomalias congênitas e a presença de alterações dermatológicas, pois é comum a associação de alterações do desenvolvimento com síndromes neurocutâneas. Atenção especial deve ser dada à palpação da região abdominal à procura de visceromegalias, que são freqüentes em uma série de patologias do desenvolvimento ${ }^{11}$.

A avaliação do sistema sensorial, principalmente da audição e visão deve ser feita desde os primeiros meses e será objeto de detalhamento quando se abordar as características de cada apresentação das deficiências.

A avaliação das habilidades da criança é parte importante no processo diagnóstico. Na literatura, são inúmeras as escalas de desenvolvimento existentes, sendo a maioria baseada na Escala de Gesell. Essas escalas têm algum valor no processo de avaliação como sistematizadoras do exame e, na nossa opinião, apenas durante os primeiros anos de vida da criança, fase em que existe predomínio do aspecto biológico-maturacional no processo de desenvolvimento. Por serem baseadas em populações de contextos culturais muito distintos, fica difícil sua aplicação em crianças maiores. Além disso, as escalas medem geralmente o que a criança faz, não sendo capaz de apreender o desenvolvimento como um processo, e nem de vislumbrar o potencial da criança ${ }^{12}$. 


\section{Principais apresentações clínicas}

Classicamente, as deficiências estão subdivididas em mental, física, sensorial - auditiva ou visual - e mista, na qual todos os tipos de déficits e limitações podem estar presentes ${ }^{1}$. Nesta classificação, achamos importante agregar os pacientes com distúrbios pervasivos do desenvolvimento.

\section{As crianças e adolescentes especiais e suas necessidades especiais}

Frente a uma criança ou adolescente com necessidades especiais, é freqüente a ocorrência de algumas condutas que podem dificultar o estabelecimento do vínculo entre o paciente, sua família e a equipe de saúde, atrasar as medidas necessárias para o diagnóstico, habilitação ou reabilitação e, por vezes, ter efeitos desastrosos no prognóstico desses pacientes.

Não é preciso que se tenha uma especialidade para acompanhar o desenvolvimento, detectar os sinais de distúrbios deste ou suprir as necessidades básicas de saúde do portador de deficiências, pois as manifestações das doenças ditas próprias da infância, das infecções virais ou bacterianas serão, na maioria dos casos, as mesmas das outras crianças, bem como seu tratamento.

De acordo com o tipo de distúrbio de desenvolvimento, normas básicas para acolhimento e atendimento precisam ser seguidas para que se obtenham o melhor prognóstico possível e a adesão do paciente e de sua família ao tratamento proposto, como demonstradas nas Tabelas 2 a $6^{14}$.

\section{Características específicas dos distúrbios de desenvol- vimento}

\section{Quando predomina a deficiência mental}

Cerca de $50 \%$ dos portadores de necessidades especiais apresentam deficiência mental. De acordo com a Associação Americana de Deficiência Mental (AAMR) ${ }^{15}$ e o manual Diagnóstico e Estatístico de Transtornos Mentais $\left(\right.$ DSMIV) ${ }^{16}$, define-se como deficiência mental o estado de redução notável do funcionamento intelectual significativamente inferior à média, que se inicia durante o período de desenvolvimento da criança e está associado a limitações em pelo menos dois aspectos do funcionamento adaptativo: comunicação, cuidados pessoais, atividades de vida diária, habilidades sociais, utilização dos recursos comunitários, autonomia, aptidões escolares, lazer e trabalho.

Nesta definição, abandonou-se a antiga classificação da deficiência mental como leve, moderada, severa ou profunda, admitindo-se que o nível de desenvolvimento alcançado pelo indivíduo dependerá não apenas do grau de comprometimento mental, mas também de sua história de vida, do apoio familiare sociale das oportunidades vivenciadas ${ }^{17,18}$.

A hipóxia perinatal e as infecções congênitas são grandes causas de deficiência mental, bem como a síndrome de Down, que é a síndrome genético-cromossômica mais fre-
Tabela 2 - Princípios gerais de conduta frente a uma criança ou adolescente portador de deficiência

1. Não tenha pressa em dar um diagnóstico etiológico definitivo. Avalie seu paciente, crie vínculos, levante a possibilidade da existência de um problema do desenvolvimento que necessita de maiores investigações e talvez, do parecer de outros profissionais.

2. O diagnóstico funcional pode e deve ser feito na primeira avaliação, para encaminhamento à intervenção com equipe multidisciplinar, evitando maiores atrasos e seqüelas.

3. O prognóstico só deve ser repassado quando terminada a avaliação completa, por equipe multidisciplinar, e após o reconhecimento de que esta família já está na fase de aceitação e recuperação.

4. Não faça profecias a respeito do prognóstico. Evite termos como "ele nunca vai andar" "Nunca vai aprender, ouvir ....". Essas profecias podem se tornar auto-realizáveis, pois a família desiste de investir no paciente. A criança em desenvolvimento com tratamento adequado é capaz de recuperações imprevisíveis, havendo vários meios de enxergar, ouvir, falar e conviver em sociedade...

5. Encaminhe sempre seu paciente para acompanhamento interdisciplinar com assistência especializada nas áreas que tem ou poderá ter limitações.

6. A assistência emocional é extremamente importante no enfrentamento inicial da deficiência e em várias outras fases do desenvolvimento da criança e adolescente.

7. Evite repetição de exames ou investigações sem finalidade de melhoria da avaliação e tratamento, que apenas causarão novos sofrimentos e aumentarão a frustração de todos quando não resultarem em novas opções de tratamento ou cura.

8. Os portadores de deficiência têm uma sensibilidade especial na compreensão do meio e dos que os rodeiam, sendo capazes de perceber o interesse ou não do profissional, mesmo nos casos mais graves.

9. A orientação para tratamento deve ser dada primeiramente ao paciente, dentro do entendimento e linguagem que lhe é acessível, e depois aos responsáveis, ressaltando a estes a importância do tratamento, porque deles depende a adesão e continuidade do acompanhamento.

10. Procure conhecer e ter disponíveis os endereços dos grupos de apoio e associações de portadores de deficiência de sua cidade. Estas associações costumam prestar um trabalho muito especial para estas famílias na aceitação da deficiência, e muitas mantêm serviços de intervenção precoce e reabilitação excelentes.

qüente ${ }^{19}$. Em meninos, deve-se lembrar da possibilidade da síndrome do $\mathrm{X}$ frágil ${ }^{19}$. A síndrome alcoólica fetal deve ser aventada em toda criança com baixo ganho pondoestatural, microcefalia, filtro nasolabial hipoplásico, lábio superior afilado, retrognatia, fenda palpebral estreita e microcefa$\operatorname{lia}^{20}$. Dentre as encefalopatias crônicas evolutivas da infância, é importante destacar os erros inatos do metabolismo e a síndrome da imunodeficiência adquirida ${ }^{19}$. 
Princípios básicos de conduta frente a um portador de deficiência mental

Os portadores de deficiência mental são geralmente bem dispostos, alegres, carinhosos e gostam de se comunicar. Têm uma sensibilidade aguçada e, muitas vezes, uma esperteza fora do habitual para avaliar o ambiente e as pessoas que os cercam. Na Tabela 3, enunciamos alguns cuidados importantes na sua abordagem ${ }^{21}$.

Problemas especiais de saúde das crianças com síndrome de Down ${ }^{22}$

As crianças com síndrome de Down apresentam maior risco de algumas anomalias congênitas e maior freqüência de alguns problemas médicos, que variam de acordo com sua faixa etária, necessitando de acompanhamento de rotina diferenciado. As anomalias e os problemas médicos mais freqüentes são descritos a seguir.

Cardiopatias: avaliação cardiológica minuciosa deve ser feita logo após o nascimento, incluindo a realização de ecocardiograma, mesmo que sua ausculta cardíaca seja normal.

Infecções: apresentam maior predisposição para quadros infecciosos, principalmente do trato respiratório, em decorrência de alterações imunológicas e pela hipotonia da musculatura respiratória. Sempre que possível, deve-se indicar a vacinação contra pneumococos, influenzae e varicela para essas crianças.

Distúrbios visuais: têm maior incidência de catarata, estrabismo, miopia, astigmatismo, hipermetropia, nistagmo, ambliopia e obstrução do canal lacrimal, devendo a avaliação oftalmológica ser feita logo após o nascimento e repetida a cada ano.
Distúrbios auditivos: a avaliação objetiva da audição deve ser realizada nos primeiros três meses de vida e repetida nos casos suspeitos ou com otites de repetição.

Problemas endocrinológicos: apresentam maior incidência de doenças da tireóide e, como em muitas situações os sinais da doença tireoideana confundem-se com a própria síndrome, é aconselhável a monitorização anual dos níveis de TSH e T4.

Problemas ortopédicos: é freqüente a ocorrência de instabilidade atlanto-axial, que é definida como a mobilidade aumentada da coluna cervical entre a primeira e segunda vértebras. Assim, indica-se a realização de radiografias da coluna cervical, com análise por profissional experiente, nas posições de flexão, extensão e neutra a partir dos 2 anos e meio, repetindo-se posteriormente, conforme necessidade.

Distúrbios psiquiátricos: distúrbios emocionais, principalmente os depressivos e doença de Alzheimer têm sido descritos com maior freqüência nestes jovens e adultos.

\section{Quando predomina a deficiência física}

Nos primeiros anos de vida, a paralisia cerebral é a deficiência física mais comum. O termo paralisia cerebral, apesar de consagrado, foi utilizado para definir uma série de patologias distintas, nem sempre com quadros de paralisias, e muitas vezes de origem não cerebral. A paralisia cerebral é uma das formas de encefalopatia crônica não evolutiva da infância. Excluem-se, portanto, todas as alterações progressivas e caracteriza-se pela presença de distúrbio motor, em decorrência de interferência no desenvolvimento do sistema nervoso central, podendo ocasionar distúrbios da movimentação voluntária, do tono muscular, hipercinesias,

Tabela 3 - Princípios básicos de conduta frente a um portador de deficiência mental

1. Naturalidade e palavras afetuosas são o melhor caminho para que eles façam vínculos, permitam o exame clínico e aceitem o tratamento.

2. A superproteção deve sempre ser evitada.

3. Cada conduta ou abordagem deve ser explicada passo a passo e não como um roteiro entregue na recepção do paciente.

4. Esses pacientes precisam de um tempo maior para compreender a necessidade de serem examinados e se sentirem seguros.

5. Observe sempre que o portador de deficiência mental não é um doente mental, ele tem uma conseqüência de uma doença ou agravo - é uma "condição de ser".

6. Tratem-nos como criança quando forem crianças e como adolescentes quando adolescentes, respeitando sua sexualidade e orientando suas famílias para fazerem o mesmo.

7. Avalie sempre se o quadro clínico atual faz parte da evolução da patologia de base, ou é uma clínica diversa que merece nova investigação e tratamento. 
freqüentemente concomitantes com distúrbios de aprendizagem, comunicação ou fala. O portador de paralisia cerebral pode ter nível de inteligência normal, e a gravidade do problema motor nem sempre corresponde ao mesmo nível de comprometimento cognitivo ${ }^{23}$.

A criança com paralisia cerebral apresenta, com freqüência, algumas particularidades que devem ser do conhecimento do pediatra, tais como:

- alterações globais do seu desenvolvimento, sendo fundamental a avaliação sistemática da audição e da visão;

- dificuldade de deglutição e, mais tarde, de mastigação;

- refluxo gastroesofágico e incoordenação cricofaríngea;

- desnutrição e desvios alimentares decorrentes da maior dificuldade de ingestão dos alimentos e dos quadros infecciosos de repetição;

- doenças respiratórias de repetição, seja pela hipotonia da musculatura respiratória, pela permanência em decúbito dorsal, ou por aspiração;

- constipação intestinal decorrente da hipotonia e dos distúrbios alimentares;

- bexiga neurogênica, sendo importante a avaliação urológica a partir dos 3 anos de idade;

- a espasticidade constante leva a alterações de postura, como a de flexão de membros superiores e hiperextensão com adução de membros inferiores, em posição de $\mathrm{X}$, o que pode acarretar encurtamentos músculo-tendinosos, imobilizações articulares e complicação bastante freqüente e dolorosa, que é a subluxação ou luxação de articulação de quadril ${ }^{23}$.

\section{Quando predomina a deficiência sensorial}

\section{Deficiência auditiva}

A OMS estima que $15 \%$ dos portadores de deficiências apresentam deficiência auditiva. A incidência de perda auditiva em neonatos saudáveis é estimada entre um a três recém-natos para cada 1.000 nascimentos, e de dois a quatro para cada 100 neonatos que necessitaram de internação em unidades de terapia intensiva ${ }^{24,25}$. Assim, a triagem auditiva deve ser realizada em todos os recém-natos, sendo indispensável e precoce nos de risco ou nos que estiveram em UTI neonatal, devendo ser executada até o terceiro mês de vida, para que o início da intervenção aconteça antes do sexto mês. A intervenção até essa idade melhora significativamente as possibilidades de aquisição da linguagem ${ }^{24-28}$. A falta de estímulo poderá ampliar as seqüelas para níveis corticais, o que impossibilitará a audição para toda vida, mesmo que os problemas periféricos sejam tratados posteriormente ${ }^{24}$.

Os fatores de risco neonatais para deficiência auditiva são semelhantes aos das deficiências em geral, acrescidos da história familiar de deficiência auditiva congênita, consangüinidade, anomalias craniofaciais, síndromes genéti-
Tabela 4 - Princípios básicos frente a um portador de deficiência física ${ }^{14,21}$

1. Cuidado na abordagem destes pacientes e com os comentários e prognósticos repassados aos pais na presença da criança ou adolescente, pois ser portador de deficiência física não pressupõe a coexistência de deficiência cognitiva.

2. Converse sempre diretamente com seu paciente, com calma, respeitando seu ritmo. Muitas vezes eles podem ter além das dificuldades de locomoção, problemas na fala e controle dos movimentos, exacerbados pelo medo ou insegurança.

3. As patologias usuais da infância devem ser tratadas da mesma forma que em outros pacientes, observando-se apenas o histórico de infecções e tratamentos anteriores e atuais, para se avaliar interação, contra-indicação ou resistência a alguns medicamentos.

4. No diagnóstico de desnutrição, avalie o grau e verifique a possibilidade de ser secundária à doença básica ou conseqüência de negligência. $\mathrm{O}$ tratamento e a abordagem com os pais será totalmente diferente em cada um dos casos.

5. Em casos de tetraplegia ou paralisia cerebral grave, oriente sobre posição adequada de alimentar, evitando a hiperextensão de cabeça que favorece a broncoaspiração.

6. Encaminhe sempre para acompanhamento interdisciplinar para evitar sequielas maiores, físicas e mentais, além das disfunções familiares.

7. Se a criança ou adolescente usa cadeira de rodas, não a toque nem manuseie sem sua autorização, pois o uso constante e a dependência fazem com que seja sentida como parte de seu corpo. Se usar muletas ou outro sistema de apoio, deixe-o sempre ao alcance de suas mãos.

8. Mantenha sempre condições de acessibilidade e lute por ela nos locais públicos de assistência à saúde. A inclusão do portador de deficiência nos ambulatórios gerais de pediatria depende primeiramente do pediatra, e depois da possibilidade de acesso aos locais de atendimento, sem constrangimentos ou limitações impostas pelo meio.

cas e o uso de drogas ototóxicas. As meningites bacterianas, as otites médias de repetição, os traumatismos cranioencefálicos e as desordens neurodegenerativas são causas importantes após o período neonatal ${ }^{24-28}$. No nosso meio, infelizmente, ainda é muito prevalente os casos secundários à rubéola congênita ${ }^{29}$.

Deve-se aventar a possibilidade de deficiências auditivas em todas as crianças com queixa de ausência de reação a sons, atraso na aquisição da fala, preferência por sons altos, características de distração constante e desatenção. As atitudes dos lactentes com deficiência auditiva muitas vezes são confundidas com o comportamento autista e, nas crianças maiores, com deficiência mental ${ }^{24,27}$.

\section{Deficiência visual}

Toda criança nos primeiros meses de vida deve ser submetida a uma avaliação ocular sistematizada. Nesse 
Tabela 5 - Princípios gerais no atendimento da criança ou adolescente com deficiência auditiva $^{14,21}$

1. Encontre algum meio de linguagem, pergunte aos pais como se comunicam com seu filho e tente! Fale sempre de frente para seu paciente, pronunciando bem as palavras, sem pressa, com seu rosto voltado em sua direção.

2. Explique sempre, por meio de gestos ou sinais, cada atitude no exame físico, permitindo que a criança veja o que está sendo feito com ela.

3. Fale em tom normal, a não ser que o paciente peça para levantar a voz.

4. Se seu paciente tentar falar com você e não for compreendido, peça para que repita ou escreva. Mesmo necessitando de um intérprete, dirija-se sempre à criança ou adolescente.

5. A presença dos responsáveis durante o exame é fundamental para que a criança se sinta segura.

período, é fundamental a avaliação do reflexo vermelho e fotomotor, fixação e acompanhamento de objetos, devendo ser encaminhadas para avaliação especializada sempre que houver alteração de reflexos, leucocoria, atraso na fixação e acompanhamento de objetos, diferença no tamanho dos globos oculares, piscar constante, fotofobia, nistagmo, desvio fixo ocular e desvio alternante que se mantém além dos 5 meses de idade ${ }^{30}$.

A retinopatia da prematuridade deve ser investigada em toda criança com peso de nascimento inferior a $1.500 \mathrm{~g}$, idade gestacional menor ou igual a 28 semanas, ou naquelas com peso entre $1.500 \mathrm{~g}$ e $2.000 \mathrm{~g}$, com quadro de instabilidade clínica, e no RN que necessitou de oxigenoterapia em altas concentrações e ou por tempo prolongado. Essas crianças devem ser submetidas a pelo menos dois exames de fundo de olho, sendo o primeiro realizado entre a quarta e a sexta semanas de vida. Este exame deve ser feito por profissional especialista da área, com oftalmoscópio biocular, para diagnóstico preciso e precoce ${ }^{31}$.
Princípios básicos de conduta frente a um portador de deficiência visual

O portador de deficiência visual desenvolve uma percepção auditiva e tátil muito maior que a população em geral; portanto alguns cuidados são necessários no seu manejo, como enumerados na Tabela 6 .

\section{Quando predominam as alterações relacionais}

A construção da subjetividade só é possível através da interação que se estabelece entre a criança, seus cuidadores e as instâncias coletivas e institucionais em que essa criança encontra-se inserida ${ }^{32}$. Para que cada criança se constitua como sujeito, é fundamental a existência de um lugar no imaginário dos outros indivíduos de seu convívio, sendo o fator mais importante para essa construção a reciprocidade estabelecida na relação com sua mãe ou substituta ${ }^{33}$. É fundamental, portanto, a observação do vínculo estabelecido entre a criança e sua mãe ou cuidadora.

Tabela 6 - Princípios básicos frente a um portador de deficiência visual ${ }^{14,21}$

1. Não é necessário falar alto com o deficiente visual. Habitualmente ele escuta melhor que a população em geral.

2. Sempre que for examiná-lo, explique antes seu procedimento e avise tudo o que for fazer antes de tocá-lo.

3. Quando estiver tratando com uma criança maior ou adolescente, na presença dos pais, pergunte a ele se deseja tocar seu rosto para conhecê-lo. Através do timbre de voz, maneira de falar e se portar, o deficiente visual faz uma imagem de quem está a sua frente, muitas vezes bastante parecida com a verdadeira.

4. Nunca use medicamentos que possam aumentar a pressão intra-ocular sem o diagnóstico adequado da patologia ocular, e sem discutir o uso com o oftalmologista responsável. 
O olhar, o sorriso e o estranhamento são marcadores importantes do desenvolvimento relacional e afetivo do bebê ${ }^{12}$.

As doenças pervasivas do desenvolvimento comportam uma série de alterações que se iniciam na infância e caracterizam-se por distúrbios na interação social, comunicação, atividade imaginativa e um pequeno repertório de atividades de interesse. Uma parte dessas crianças apresenta déficits cognitivos, sendo o autismo a doença mais grave deste amplo espectro de entidades. O diagnóstico de autismo pode ser feito desde os primeiros meses de vida, através de falhas nos marcadores do desenvolvimento afetivo ${ }^{34}$. Essas crianças geralmente apresentam evolução normal das habilidades motoras, com grande comprometimento da linguagem ${ }^{34}$.

\section{A criança, $o$ adolescente e sua família frente à deficiên- cia}

A maioria das crianças que chega ao ambulatório de pediatria apresenta distúrbios do desenvolvimento secundários a fatores desencadeantes durante o período pré, peri ou neonatal. Assim, estas alterações instalaram-se precocemente, e a criança já inicia sua relação com o mundo com suas dificuldades e limitações. O luto da perda de uma criança saudável é de seus familiares.

Nas crianças maiores e adolescentes, agregam-se as causas externas, infecciosas e degenerativas. Nesses casos, o luto não é apenas da família, mas da própria criança que necessita se adaptar às limitações impostas a um corpo e mente anteriormente sadios. O luto maior, portanto, é do paciente, sendo o dos pais secundário, instalando-se a revolta, depressão e até o desejo de morte em muitas destas crianças e adolescentes.

A notícia de um distúrbio do desenvolvimento desencadeia uma série de reações, na dependência do modo com que este diagnóstico e prognóstico são apresentados e o apoio que esta família recebe, principalmente no primeiro momento, da equipe de saúde envolvida.

Frente a um diagnóstico de risco ou de deficiência, a reação inicial é de dúvida ou negação - "deve haver algum engano, eu não fiz nada de errado para receber isto". Como conseqüência, segue-se a procura de outros profissionais e o pedido de todos os exames possíveis, na tentativa de encontrar algum outro diagnóstico ou esperança de cura.

Quando o diagnóstico é reafirmado, vem o sentimento de culpa - "o que eu fiz de errado? O que eu fiz durante a minha vida para merecer isto?". São sentimentos trazidos da memória de toda uma existência, na busca de uma razão para a perda de um sonho, que era o filho saudável, ou, na deficiência adquirida, a perda do corpo "normal".

Segue-se a fase da revolta - "por que logo comigo?-em que tudo e todos são culpados, e o pediatra há que estar atento para reconhecê-la, pois é uma fase de extrema agressividade no relacionamento destes pais e do portador de deficiência com os profissionais aos quais têm acesso -

\author{
"o que os médicos ou os outros fizeram de errado comigo \\ ou com meu filho?".
}

Após a revolta, quando não se pode mais negar, culpar ou lutar contra, vem a necessidade de encarar a realidade e com isto a tristeza profunda, o luto da perda, que pode evoluir para depressão, impossibilitando a adesão a qualquer tratamento. Do luto, vem a aceitação, que nem sempre acontece, e dela, a recuperação. Muitas famílias ou portadores de deficiência fixam-se em algumas destas fases, como a da revolta ou culpa, buscando sempre novos exames, diagnósticos, ou curas milagrosas, não conseguindo assumir plenamente qualquer tratamento proposto.

É fundamental que se reconheça em que fase a família e o paciente estão, respeitando esta evolução, nunca encarando como um problema pessoal, porque ela é natural e necessária para que se chegue à última, da recuperação, que é a da busca do que é possível, com engajamento nos tratamentos propostos, na habilitação e reabilitação, para que esta criança ou adolescente possa ser aceito por ele mesmo e pelos seus responsáveis, como realmente é, com dificuldades, mas também com possibilidades, que, com apoio, poderão compensar ou até superar as limitações e, principalmente, manter uma qualidade de vida digna.

\section{Tratamento e reabilitação}

Com exceção de alguns erros inatos e infecções congênitas, não existe um tratamento único e específico para os distúrbios do desenvolvimento.

Os novos conhecimentos sobre a plasticidade cerebral humana reiteram a necessidade da equipe de saúde intervir precocemente e não profetizar prognósticos para esses pacientes. A estimulação nos três primeiros anos de vida, para crianças com atraso no desenvolvimento já estabelecidos ou aquelas com risco de atraso, melhora sua performance, devendo ser incentivado o seu início o mais cedo possível.

A reabilitação é o processo destinado a permitir que a pessoa deficiente alcance um nível físico, mental e/ou social funcional ótimo, proporcionando-lhe assim os meios de modificar a própria vida. Assim, todo trabalho de reabilitação deve estar centrado nas habilidades da pessoa, cuja integridade e dignidade devem ser respeitadas. Ao planejar os programas de reabilitação e de apoio, é essencial levarse em conta os costumes, possibilidades e as estruturas da família e da comunidade, fomentando sua capacidade de resposta às necessidades da pessoa deficiente.

Nesse contexto, os serviços de reabilitação deveriam estar incorporados de forma descentralizada à rede de serviços de saúde e incluírem não apenas a assistência multidisciplinar, mas também a participação das comunidades e das famílias.

\section{Inclusão}

A inclusão dessas crianças e adolescentes na comunidade é parte fundamental de sua terapêutica. Inclusão signifi- 
ca a possibilidade de oportunidades iguais às de toda a população. É preciso assegurar que o sistema geral da sociedade - o meio físico e cultural, habitação, transporte, serviços sociais e de saúde, oportunidades de educação e trabalho, vida cultural e social - seja acessível a todos. Em grande parte, o que determina o efeito de uma determinada deficiência na vida das pessoas é a experiência com o seu meio. Assim, não bastam políticas públicas voltadas apenas para a reabilitação do indivíduo portador de deficiência, mas mecanismos que lhe assegurem eqüidade de participação nos diversos aspectos da vida em sociedade.

Conclui-se, portanto, que ao afirmarmos que essas crianças e adolescentes são sujeitos de direitos, não significa apenas assegurar-lhes os direitos às suas particularidades, mas o direito à sua participação no coletivo, à vivência das diferenças e da sua singularidade, enquanto um sujeitocriança, inserido numa trajetória individual, social e cultural de seu momento histórico.

\section{Referências bibliográficas}

1. OMS - Organização Mundial da Saúde - Programa de ação Mundial para as Pessoas com Deficiência - Resolução 37/52 de 03 de dezembro de 1982 - Assembléia Geral das Nações Unidas.

2. IBGE - Instituto Brasileiro de Geografia e Estatística, 2002. Censo demográfico 2000, Rio de Janeiro.

3. Brasil. Ministério da Saúde - Secretaria de Assistência à Saúde - Coordenação de Atenção a Grupos Especiais - Atenção à Pessoa Portadora de Deficiência no Sistema de Saúde: Planejamento e organização de serviços. Brasília: Secretaria de Assistência à Saúde, 1993, 48p.

4. Marcondes E, Machado DVM, Setian N, Carrazza FR. Crescimento e desenvolvimento. In: Marcondes E, coordenador. Pediatria básica. $8^{a}$ ed. São Paulo: Sarvier; 1991.p.35-62.

5. Brasil. Ministério da Saúde. Secretaria de Políticas de Saúde. Área Técnica da Criança. Fundamentos técnicos-científicos e orientações práticas para o acompanhamento do crescimento e desenvolvimento - vol.2; Brasília: MS. No prelo 2002.

6. Allen MC. The high-risk infant. Ped Clin N Am 1993;40:479-90.

7. Halpern R, Giugliani ERJ, Victora CG, Barros FC, Horta BL. Fatores de risco para suspeita de atraso no desenvolvimento neuropsicomotor aos 12 meses de vida. J Pediatr (Rio J) 2000;76:421-8.

8. Sameroff AJ Environmental risk factors in infancy. Pediatrics 1998;102:1287-92.

9. Andraca I, Pino P, La Parra A, Rivera F, Castillo M. Factores de riesgo para el desarrollo psicomotor en lactantes nacidos en óptimas condiciones biológicas Rev Saude Pública 1998; 32:138-47.

10. Graminha SSVG, Martins MAO. Condições adversas na vida de crianças com atraso no desenvolvimento. Medicina (Ribeirão Preto) 1997;30:259-67.

11. Levy SG, Hyman SL. Pediatric assessment of the child with developmental delay. Ped Clin N Am 1993;40:465-77.

12. Sucupira ACSL, Werner J Jr, Resegue R. Desenvolvimento. In: Sucupira ACSL, Bricks LF, Kobinger MEBA, Saito MI, Zuccoltto SMC, coordenadores. Pediatria em consultório. $4^{\mathrm{a}}$ ed São Paulo: Sarvier; 2000.p.22-39.
13. Glascoe FP. Evidence-based approach to developmental and behavioral surveillance using parents' concerns. Child Care Health Dev 2000;26:137-49.

14. Centro Regional de Assistência Integrada à Criança e Adolescente Portadores de Deficiências. Protocolos de Atendimento Secretaria de Estado da Saúde - Curitiba, Paraná; 1999.

15. Luckasson R, Coulte DL, Polloway EA, Reiss S, Schalock RL, Snell ME, et al. Mental retardation: definition, classification and systems of supports. 9a ed. Washington: AAMR; 1997.

16. Manual Diagnóstico e Estatístico de Transtornos Mentais. DSMIV. $4^{\text {a }}$ ed. Porto Alegre: Artes Médicas; 1995.

17. Verdugo MA. El cambio del paradigma en la concepción del retraso mental: la nueva definición de la AAMR. Siglo Cero 1994;25:5-24.

18. Verdugo MA. Avances conceptuales actuales y del futuro inmediato: revisión de la definición de 1992 de la AAMR. Siglo Cero 1994;30:27-31.

19. Diament, A. Deficiência Mental. In: Cypel S, Diament A, editores. Neurologia Infantil. $3^{a}$ ed. São Paulo: Atheneu; 1996.p.799-814.

20. Nordberg L, Rydelius PA, Zetterström R. Children of alcoholic parents: health, growth, mental development and psycopathology until school age. Acta Paediatr Suppl 1993;387:1-21.

21. Brasil Ministério da Ação Social e Justiça. CORDE. "Como você deve se comportar diante de uma pessoa que...". Ministério da Ação Social. Brasília, DF; 1994.

22. Mustacchi Z, Rozone G. Síndrome de Down: aspectos clínicos e odontológicos. São Paulo: CID Editora; 1990.

23. Diament A. Encefalopatias Crônicas da Infância (Paralisia Cerebral). In: Cypel S, Diament A, editores. Neurologia Infantil. $3^{a}$ ed. São Paulo: Atheneu; 1996.p.781-98.

24. Comitê Brasileiro sobre Perdas Auditivas na Infância, 2000.

25. Yoshinaga-Itano C, Sedley A, Coulter D, Mehl A. Language of early- and later-identified children with hearing loss. Pediatrics 1998;102:1161-71.

26. National Institutes of Health Consensus Statement. Early identification of hearing impairment in infants and young children. NIH Consensus Statement 1993;11:1-24.

27. Joint Committee on Infant Hearing 1994 Position Statement. ASHA 1994;36:38-41.

28. American Academy of Pediatrics - Task Force on Newborn and Infant Hearing. Newborn and Infant Hearing Loss: Detection and Intervention. Pediatrics 1999;103:527-30.

29. Pfeiffer L. Rubéola Congênita, Um Mal Desnecessário. Boletim Epidemiológico de Curitiba, 1994.

30. King RA Common ocular signs and symptoms in childhood. Ped Clin N Am 1993;40:753-66.

31. American Academy of Pediatrics - Screening Examination of Premature Infants for Retinopathy of Prematurity. Pediatrics 2001:108:809-11.

32. Guattari F. Linguagem, consciência e sociedade. In: Guattari F, Deleuze G, coordenadores. Saúde Loucura 2. $3^{\mathrm{a}}$ ed. São Paulo. Hucitec; 1990.p.3-17.

33. Safra G. Corpo e imagem: em busca da presença. In: Comparato MCZ, Monteiro DSF, organizadores. A criança na contemporaneidade e a psicanálise, II. São Paulo. Casa do Psicólogo; 2001.p.17-24.

34. Mazet P, Stoleru S. Grandes agrupamentos nosográficos. In: Mazet P, Stoleru S. Manual de psicopatologia do recém-nascido. $1^{a}$ ed. Porto Alegre: Artes Médicas; 1990.p.210-50.

35. OMS - Organização Mundial da Saúde - Normas sobre Equiparação de Oportunidades para as Pessoas com Deficiência. - Resolução 48/96 de 20 de dezembro de 1993 - Assembléia Geral das Nações Unidas. 
36. Prefeitura do Município de São Paulo - Secretaria Municipal de Saúde. Caderno Temático da Criança, 2002.

37. Lira MI, Gálvez G. El programa de estimulación precoz: diez años despues de una experiencia piloto. In: Cusminsky M, Moreno E, Ojeda ENS, editores Crescimiento y desarollo: hechos y tendencias. OPS/OMS Publicación científica no. 510. Washington:OPS/OMS1988.p.383-404.

38. Berlin LJ, Brooks-Gunn J, McCarton C, McCormick MC. The effectiveness of early intervention: examining risk factors and pathways to enhanced development. Preventive Medicine 1998; 27:238-45.
39. Garcia-Navarro ME, Tacoronte M, Sarduy I, Abdo R, Galvizú R, Torres A, et al. Influencia de la estimulación temprana en la parálisis cerebral. Revista de Neurología 2000;31:716-9.

Endereço para correspondência:

Dra. Luci Pfeiffer

Av. Visconde de Guarapuava, 3211 - Centro

CEP 80010-100 - Curitiba, PR

E-mail: lucipfeiffer@aol.com 